\title{
Evaluating Material Flammability in Microgravity and Martian Gravity Compared to the NASA Standard Normal Gravity Test
}

\author{
S.L. Olson ${ }^{* 1}$ and P.V. Ferkul ${ }^{2}$ \\ ${ }^{1}$ NASA Glenn Research Center, Cleveland, OH 44135 \\ ${ }^{2}$ National Center for Space Exploration Research, Cleveland, OH 44135
}

\begin{abstract}
Drop tower tests are conducted at Martian gravity to determine the flammability of three materials compared to previous tests in other normal gravity and reduced gravity environments. The comparison is made with consideration of a modified NASA standard test protocol. Material flammability limits in the different gravity and flow environments are tabulated to determine the factor of safety associated with normal gravity flammability screening. Previous testing at microgravity and Lunar gravity indicated that some materials burned to lower oxygen concentrations in low gravity than in normal gravity, although the low g extinction limit criteria are not the same as 19 due to time constraints in drop testing. Similarly, the data presented in this paper for Martian gravity suggest that there is a gravity level below Earth's at which materials burn more readily than on Earth. If proven for more materials, this may indicate the need to include a factor of safety on $1 \mathrm{~g}$ flammability limits.
\end{abstract}

\section{Introduction}

$\mathrm{C}$ urrently, NASA STD 6001 Test 1 is the major method used to assess flammability of materials intended for use conducted in the most severe flaming combustion environment (oxygen concentration, pressure) expected in the spacecraft (e.g. currently $30 \%$ oxygen at 10.2 psia which is the pre-breath environment on the ISS for spacewalks). Materials that do not self-extinguish after six inches of burning must undergo other special considerations and/or tests if they are to be used on spacecraft. To better understand the actual spacecraft flammability limits, a modified Test 1 protocol has been evaluated with 3 materials in Martian gravity $(0.38 \mathrm{~g}$ Earth $)$ and compared to earlier related tests at $1 \mathrm{~g}$, Lunar g, and microgravity with forced convection. This modified Test 1 protocol relies on performing multiple tests in 1-g (refs. 2-4). For reduced gravity tests, the protocol is modified slightly (as described later) because of the number of drop tower tests which would be required.

This protocol, rather than qualifying materials as pass/fail in the worst-expected environments, measures the actual upward flammability limit (akin to the Limiting Oxygen Index (LOI)) for the material so that a more accurate assessment of the margin of safety of the material in the real use environment can be made. In broader application, the modified Test 1 protocol would provide the option of selecting better or best materials based on the best margin of safety relative to the use environment, as opposed to what would be considered just "passing" from a flammability point of view.

For future space missions, it is often desirable to reduce cabin pressure while maintaining oxygen partial pressure. ${ }^{5}$ Atmospheres are chosen based on several considerations including: material flammability, decompression sickness, hypoxia, and efficient crew transfers and excursions. Keeping oxygen partial pressure constant while reducing total pressure has the effect of increasing the concentration of oxygen which in turn leads to increased flammability of materials.

One of the major lessons learned from the Apollo 1 fire is that it is impossible to eliminate all ignition sources, ${ }^{6}$ so fire prevention is achieved in spacecraft through material controls near potential ignition sources and the use of fire resistant materials. After Skylab, the Space Shuttle and the International Space Station (ISS) have operated at normal sea-level conditions (air, 21\% oxygen and $79 \%$ nitrogen by volume at 14.7 psia total pressure) except for brief pre-EVA activities when oxygen levels are increased for a short period of time to $30 \%$ oxygen while the total 
pressure is lowered to 10.2 psia. Many of the materials which had been used in the Shuttle or which are currently used in ISS are therefore only tested and rated to $30 \%$ oxygen at 10.2 psia.

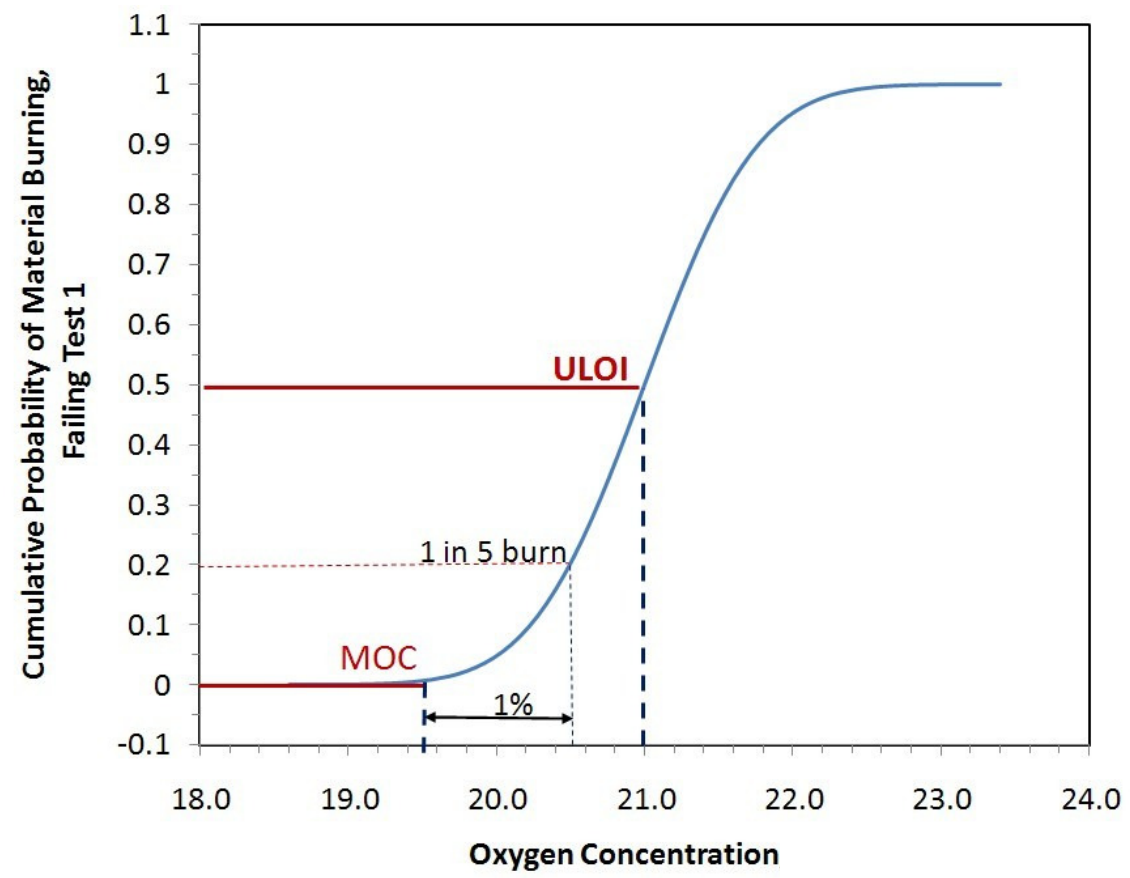

Figure 1. Near limit probability that a material will burn or not, with the ULOI and MOC indicated.

In the modified procedure, ${ }^{2}$ the oxygen concentration in Test 1 is successively reduced to identify the Upward Limiting Oxygen Index (1g ULOI) and the Maximum Oxygen Concentration (1g MOC) that consistently results in self-extinguishment of the material. The $1 \mathrm{~g}$ ULOI is defined as the oxygen concentration at which a material passes the NASA STD 6001 Test 1 burn length criterion approximately half the time. The $1 \mathrm{~g}$ MOC is defined as the oxygen concentration where at least five samples passed the burning criterion (according to the NASA STD 6001 Test 1 definition) and where at least one sample failed in the environment that contained 1 percent more oxygen by volume. This is shown schematically for an arbitrary material in Fig. 1. For reduced gravity tests, the definitions of MOC and ULOI are modified slightly (as described later) because of the number of drop tower tests which would be required.

\section{Experiment Description}

To better understand a material's flammability limits at reduced gravity, we evaluate three materials in Martian-g using the centrifuge described below. These tests are combined with 1g tests performed at NASA's White Sands Test Facility (WSFT), microgravity tests with forced convection, and Lunar-g tests at NASA's Glenn Research Center.

The centrifuge was developed for use in a drop tower environment. The apparatus is subject to the usual constraints on size and volume for the Zero Gravity Facility at the NASA Glenn Research Center. ${ }^{7}$ The centrifuge consists of a flat circular base (turntable) and the chamber dome.

Most experiments examining fluid and gas flows require a chamber for containment and atmosphere, since the drop tower is evacuated before a drop. The chamber was designed to maximize the rotation radius possible on the drop bus. The strength of the chamber was built to permit tests up to $2 \mathrm{~atm}$ absolute pressure. A photograph of the chamber is shown in Fig. 2. More details are provided elsewhere. ${ }^{8}$

The fuels used include Ultem ${ }^{\circledR} 1000$, Nomex ${ }^{\circledR}$ HT90-40, and Mylar® G or Melinex ${ }^{\circledR}$ 515. These three materials were evaluated for microgravity, Lunar, and Martian flammability limits to compare with the $1 \mathrm{~g}$ ULOI and $1 \mathrm{~g}$ MOC.

Ultem ${ }^{\circledR} 1000$ (fire retarded polyetherimide (PEI)) in 10 mil thick film is inherently flame-retarding, with charring characteristics, a very low smoke signature, very low smoke toxicity, and a low heat-release rate. 


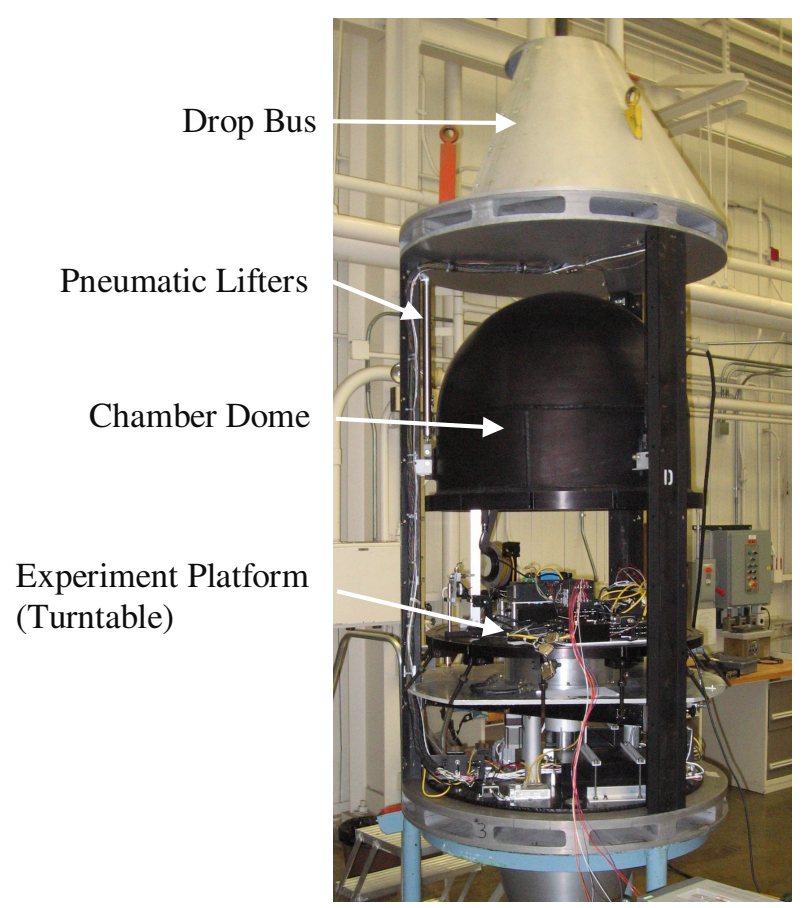

Figure 2. Zero-Gravity Centrifuge.

Nomex ${ }^{\circledR}$ HT90-40 is a 12 mil thick fire retarded aromatic nylon fabric which does not melt or drip as it burns. When exposed to a heat source, the Nomex fibers swell and seal the spaces between the fibers, stopping air movement through the fabric and thus inhibiting heat transfer through the fabric.

Mylar® $\mathrm{G}$ is a 5 mil thick plastic film made from polyethylene terephthalate. It is not fireretarded, melts as it burns, and was selected primarily for its non-charring character. The WSTF comparison tests used Melinex ${ }^{\circledR}$ 515, a very similar Dupont Teijin film.

The solid fuel sample was mounted within the chamber as shown schematically in Fig. 3. The fuel sheet is mounted parallel to the turntable and near the outer periphery. It is sandwiched between two 0.005 "-thick mica rectangular frames $(5 \mathrm{~cm} \mathrm{x}$ $15 \mathrm{~cm}$ opening) which are in turn sandwiched between 0.010 "-thick stainless steel rectangular frames. The fuel is ignited with a hot wire at the furthest point from the center so that a concurrentflow flame spread geometry is established.

The chamber is filled to the desired atmosphere. Prior to the drop, the chamber is rotated for at least five minutes to allow the interior gases to come up to speed (solid body rotation). To achieve Martian gravity levels, the rotation rate required is 30.8 RPM. Martian g-level is achieved at the radial distance of the igniter.

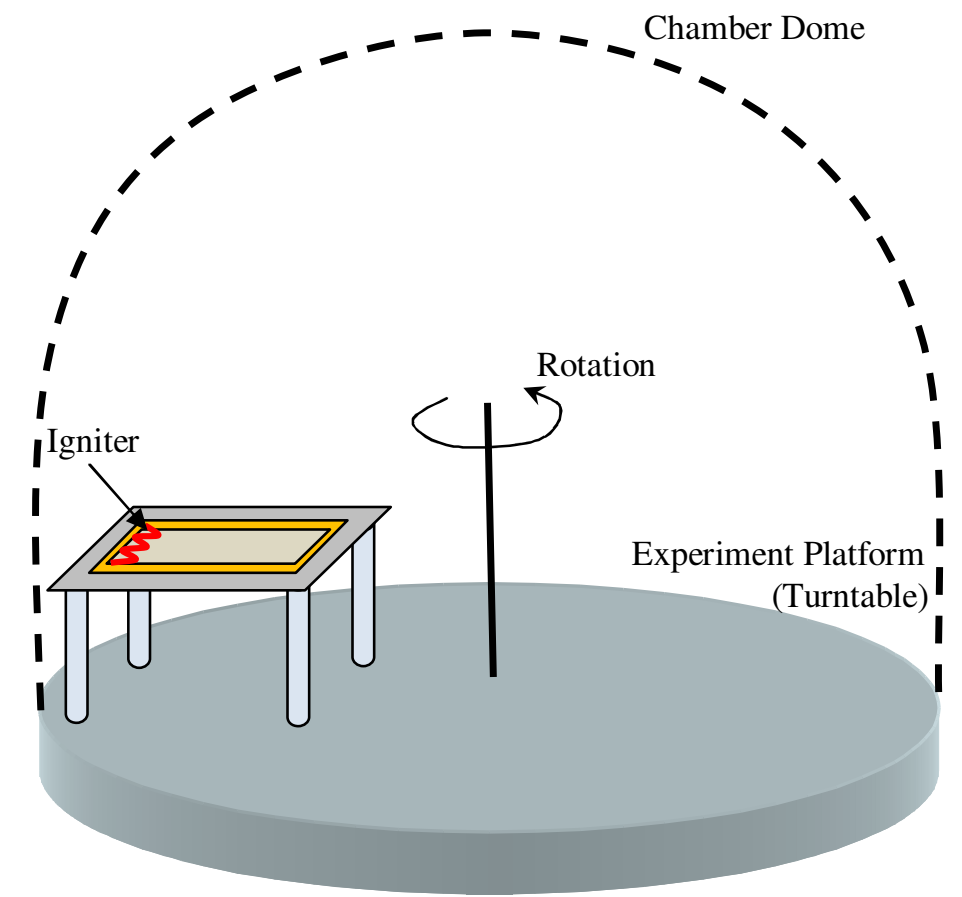

Figure 3. Schematic of Zero-Gravity Centrifuge showing fuel location; buoyant flow is toward the center of the turntable.

In order to maximize available drop time, the goal was to get the samples ignited right at or slightly before the drop. For the Ultem and Nomex samples, the igniter current was initiated 2.1 seconds before drop and was on for a 
total of 3.5 seconds. For the Mylar samples, ignition was easier to achieve. The igniter current was initiated 1 second before the drop and was on for a total of 2 seconds. The Mylar sample ignitions were assisted using a small strip of thin tissue paper (Kimwipes, $0.5-\mathrm{cm}$ width) which helped provide a uniform energy deposition to this melting fuel. For all cases, the average igniter power was 58 watts. All the Martian-g cases used the same igniter wire.

Experiments were then conducted to examine the maximum oxygen concentration at which three different materials burning in Martian gravity would self-extinguish. (Experiment materials and test conditions were chosen to match earlier tests performed at WSTF, described below.) Slightly different than the 1-g definitions of MOC and ULOI, the MOC* for these tests was defined as the maximum oxygen concentration at which the flame was observed to self-extinguish during the drop time. The ULOI* criterion was minimum oxygen concentration where the flame survived the full drop time. Images of the ULOI* conditions for each are shown in Fig. 4. The Mylar flame appeared stable (as shown later in Fig. 5) but the Nomex and Ultem flames were becoming quite dim and shrinking at the end of the drop (less than $1 \mathrm{~cm}$ in length and getting smaller). Since it is likely that these very weak flames might have extinguished given longer time in Martian g, the limits found are conservative. ${ }^{\text {a }}$
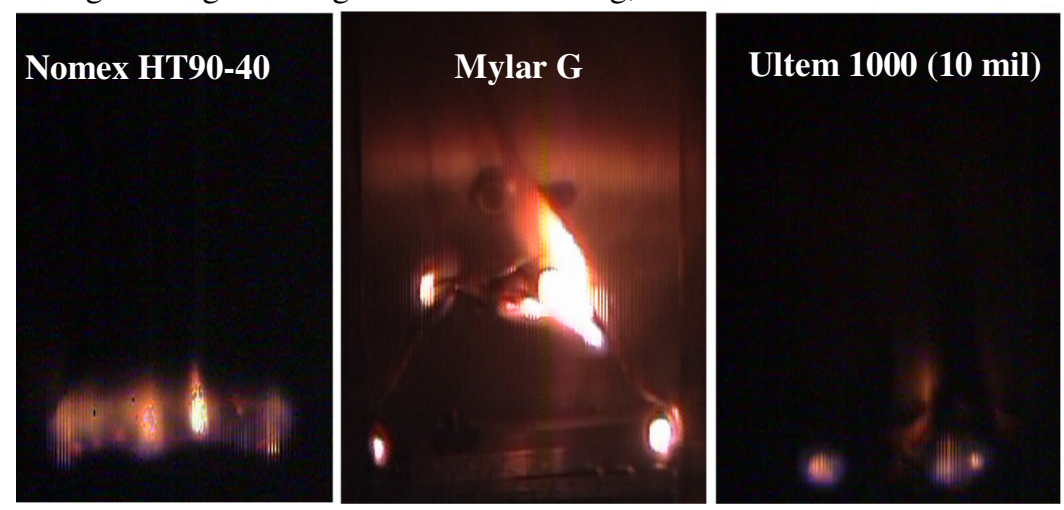

Figure 4. Front view pictures of Martian gravity concurrent flames for three different fuels samples at the ULOI just as the drop ends $(t=5.18 \mathrm{~s})$.

The NASA WSTF tests were conducted using the STD-6001 Test 1 protocol except a hot wire igniter is used to ignite the samples instead of a chemical igniter, to better compare with the low gravity results. This is because the chemical igniter provides heat for 25 seconds, and the longest low gravity time is 5 seconds. In addition, the atmosphere of the test was modified to find the ULOI and MOC as described earlier.

\section{Results}

Materials flammability tests were conducted for three materials at Martian-g. The results were compared to ULOI and MOC values in 1-g, Lunar-g, and $0 \mathrm{~g}$ (with a concurrent flow of $30 \mathrm{~cm} / \mathrm{s}$, which is a reasonable maximum local spacecraft ventilation velocity ${ }^{9}$.

Representative flame images are shown in fig. 5 for Mylar burning at the Martian-g ULOI* condition $\left(18 \% \mathrm{O}_{2}\right.$ at $10.2 \mathrm{psi}$ ). The igniter can be seen glowing on the left side of the frame until ignition. Igniter power is then turned off and the igniter cools. The flame starts out as dim blue but then brightens to yellow and actually appears to stabilize. While the flame does not span the 5 - $\mathrm{cm}$ width of the sample, it survives for the duration of the drop test. When the oxygen is decreased in another test to $17 \%$, the flame goes out.

${ }^{a}$ The flames in these Martian-g centrifuge tests were relatively small compared to the sample size and spread only a short distance along the available fuel in the $5.18 \mathrm{sec}$-duration drop tower tests. Since the local centrifugal acceleration level is proportional to radius from the center of rotation, this means that the flame stays in a region of approximately constant g-level (lunar g). On the other hand, if the flame were to spread a significant way along the fuel, the local acceleration level experienced by the flame would change appreciably as it spread. 


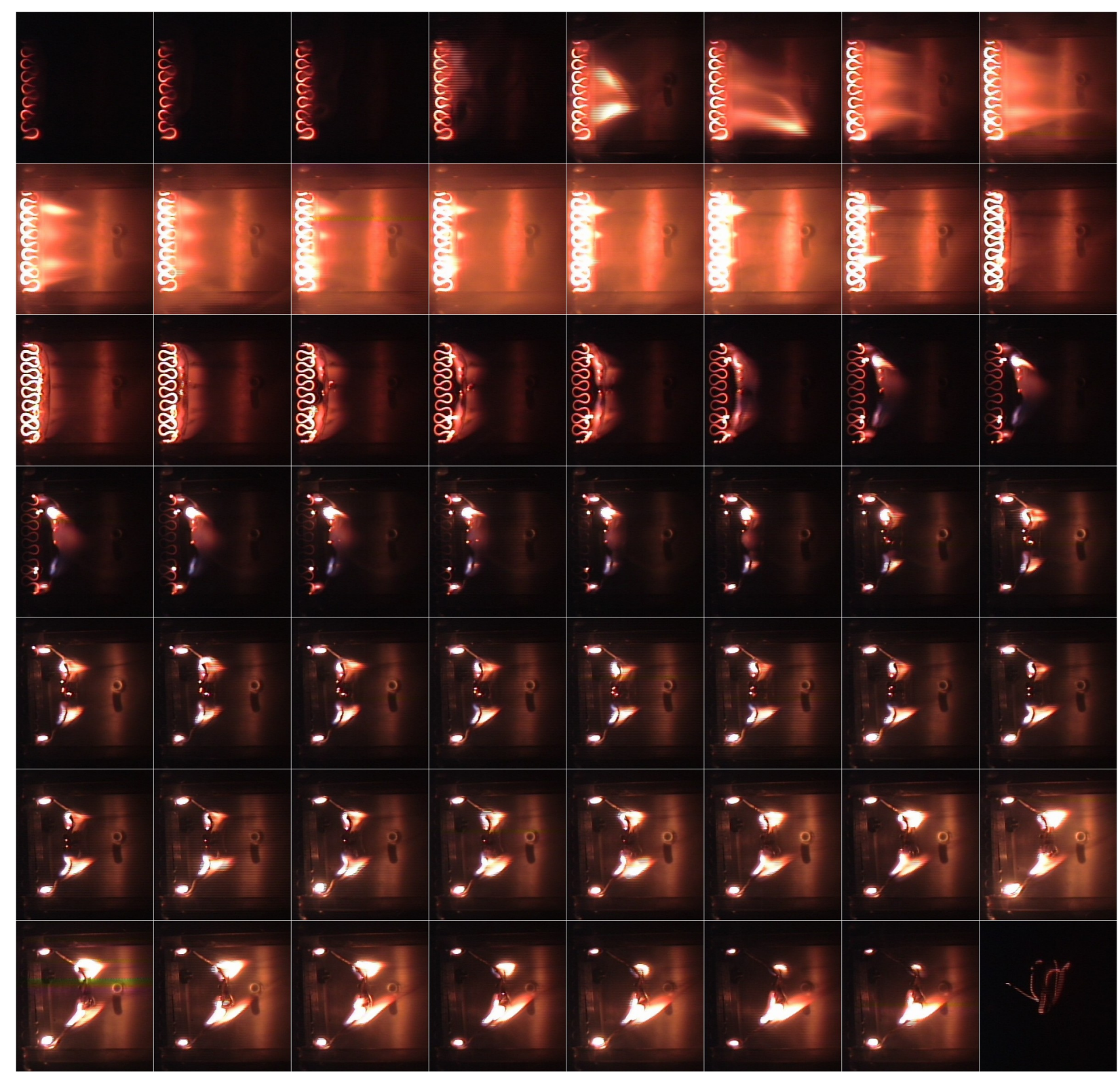

Figure 5. Flame images for Mylar at the Martian-g ULOI*. Images are shown at $10 \mathrm{~Hz}$ progressing left to right then top to bottom. The last frame shows flame extinction caused by impact of the experiment.

The limiting oxygen values (ULOI and MOC) for each fuel are summarized in Table I (includes earlier data from ref. 8). We reiterate that the definition of MOC* and ULOI* are slightly different in reduced gravity (compared to MOC and ULOI definitions in normal gravity) because of the number of drop tower tests which would be required. The near-limit flames are generally small and localized to the upstream edge of the material. We noticed that any distortion of the burned edge of the material, such as curling, swelling, or contracting, weakens the flame apparently by influencing the flow around the burned edge. Since oxygen transport is critical to low gravity flames, anything that reduces the free flow of oxygen past the sample will reduce the material's flammability. 
Table I: Limiting Oxygen Molar Concentrations and Oxygen Margin of Safety for Different Gravity Levels

\begin{tabular}{|c|c|c|c|}
\hline Fuel & $\begin{array}{c}\text { Mylar }{ }^{\circledR} \mathbf{G} \\
10.2 \text { psia }\end{array}$ & $\begin{array}{c}\text { Ultem }^{\circledR} 1000 \\
10.2 \text { psia }\end{array}$ & $\begin{array}{c}\text { Nomex }^{\circledR} \text { HT90-40 } \\
14.7 \text { psia }\end{array}$ \\
\hline 1g ULOI & 21.2 & 23.5 & 23.5 \\
\hline $1 \mathrm{~g} \mathrm{MOC}$ & 20.0 & 23.0 & 22.1 \\
\hline Martian ULOI* & 18.0 & 22.0 & 19.9 \\
\hline Martian MOC* & 17.0 & 21.1 & 19.0 \\
\hline Lunar ULOI* & 15.6 & 21.0 & 21.0 \\
\hline Lunar MOC* & 14.1 & 19.9 & 19.9 \\
\hline $0 \mathrm{~g} * \mathrm{ULOI}^{*}$ & 17.0 & 24.0 & 23.0 \\
\hline $0 \mathrm{~g} * \mathrm{MOC}^{*}$ & 16.0 & 23.0 & 22.0 \\
\hline Martian $\Delta \mathrm{O}_{2} \%$ & -3.1 & -1.7 & -3.35 \\
\hline Lunar $\Delta \mathrm{O}_{2} \%$ & -5.75 & -2.8 & -2.35 \\
\hline $0 \mathrm{~g} \Delta \mathrm{O}_{2} \%$ & -4.1 & 0.25 & -0.3 \\
\hline
\end{tabular}

From the limit data, we can evaluate the oxygen margin of safety of the material in low gravity relative to the $1 \mathrm{~g}$ Test 1 data. The oxygen margin of safety, or $\Delta \mathrm{O}_{2} \%$, is defined here as the mean $0 \mathrm{~g}$ limit or the Lunar limit minus the mean $1 \mathrm{~g}$ limit as follows:

$$
\Delta O_{2} \%=\left(\frac{\left(U L O I^{*}+M O C^{*}\right)}{2}\right)-\left(\frac{\left(U L O I_{1 g}+M O C_{1 g}\right)}{2}\right)
$$

In Eq. (1), the lowest $\% \mathrm{O}_{2}$ at which the material burned in the drop test for the full test time was taken as the $0 \mathrm{~g}$ Lunar-g, or Martian-g ULOI*; the maximum $\% \mathrm{O}_{2}$ where the material extinguished during the drop test was taken as the $0 \mathrm{~g}$, Lunar-g, or Martian-g MOC*. It should be noted that the low g extinction limit criteria are not the same as $1 \mathrm{~g}$ due to time constraints in drop testing. A positive $\Delta \mathrm{O}_{2} \%$ means that the flame will burn in $1 \mathrm{~g}$ at lower oxygen concentrations than in low gravity (Lunar or $0 \mathrm{~g}$ ). Conversely, a negative $\Delta \mathrm{O}_{2} \%$ means that the flame will propagate in Lunar or $0 \mathrm{~g}$ at a lower oxygen concentration than in $1 \mathrm{~g}$ and as reflected by the negative margin of safety. Values of $\Delta \mathrm{O}_{2} \%$ for both $0 \mathrm{~g}$ and Lunar $\mathrm{g}$ (from ref. 8) are included in Table I. 


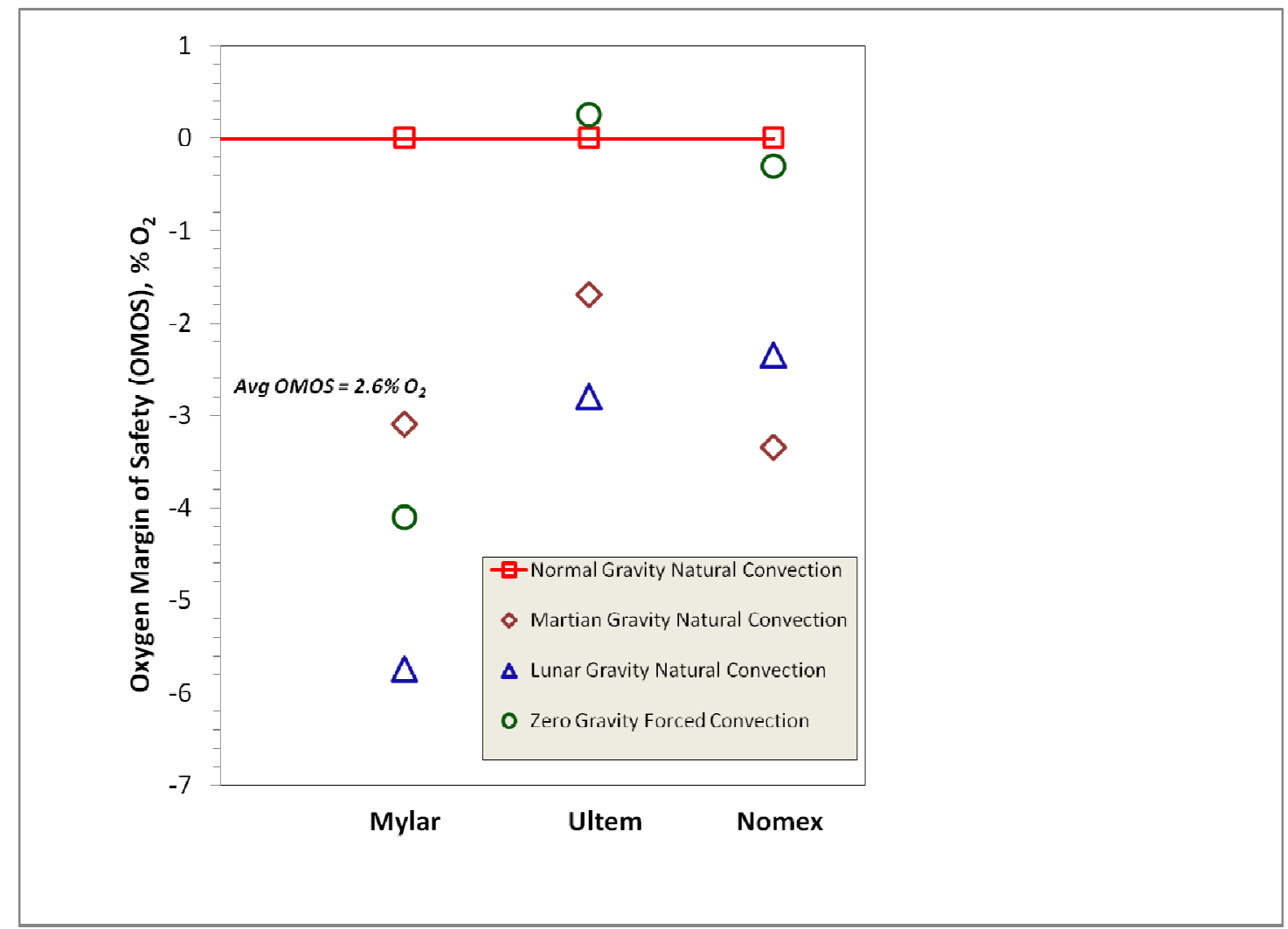

Figure 6. Oxygen Margin of Safety for four different gravity levels. The squares are normal gravity data which by definition has zero oxygen margin of safety since it is the test standard upon which materials are assessed. Martian, lunar, and microgravity oxygen margins of safety are generally negative by as much as $-5.75 \% \mathrm{O}_{2}$ in molar concentration. The average $0 \mathrm{~g}$ oxygen margin of safety for these three materials is $\mathbf{- 2 . 6 \%}$ and the average Martian oxygen margin of safety is $\mathbf{2 . 7 \%}$.

As shown in Fig. 6 and Table I, the 1g flammability limits are generally not conservative for these materials as evidenced by the negative $\Delta \mathrm{O}_{2} \%$, by up to $-5.75 \%$ oxygen. For low gravity concurrent (upward) flow conditions, the absence of or reduction of buoyancy reduces convective heat loss from the flame zone. As such, the flame doesn't have to release as much heat as in $1 \mathrm{~g}$ to provide the same amount of heat flux to the unburned fuel. Thus, it is not entirely surprising that the low gravity flammability limits are lower than the $1 \mathrm{~g}$ flammability limits, which is the general trend. The evaluation of the magnitude of this $\Delta \mathrm{O}_{2} \%$ for other materials is continuing for concurrent flammability limits, to be followed by evaluation of the limits for opposed flow. If proven for more materials, this may indicate the need to include a factor of safety on $1 \mathrm{~g}$ flammability limits.

Nomex and Ultem are charring fuels. Char layer formation is a known fire-retardant mechanism since it reduces the heat release rate of the material. For these charring materials, the oxygen margin of safety in $0 \mathrm{~g}$ is very close to zero, indicating that any reduced charring for $0 \mathrm{~g}$ may be offset by less heat release in the reduced convective environment. In Lunar gravity, the oxygen margin of safety for these charring fuels is $\sim 2.5 \%$ lower than $1 \mathrm{~g}$. It may be that with adequate but not excessive convection, materials burn better, as predicted by flammability maps. ${ }^{10}$

Mylar is a non-charring material. Just as for metals combustion ${ }^{11}$ the absence of gravitational-induced dripping keeps heated molten fuel in the flame zone rather than removing it, and the result is a significantly negative oxygen margin of safety $(\sim 4-5 \%)$ in Martian, Lunar, and $0 \mathrm{~g}$.

In fig. 7, limiting oxygen concentration is plotted for Mylar as a function of gravity level. There appears to be a range of g-levels within which a flame can survive. This is similar to the forced convective flammability boundary ${ }^{10}$. The two u-shaped curves are presumed to bound the flammability boundary of this material. Fig. 7 includes additional two data points at sub-lunar g-levels to probe the behavior at low flow speeds, including one test at a g-level equaling that on Pluto. Tests were conducted using precision mixtures of gases $\left(+/-0.1 \% \mathrm{O}_{2}\right)$ but at 
increments of $1 \% \mathrm{O}_{2}$. Given the sparcity of points, the exact shapes of the curves are not known, nor are the absolute minimums. However the curves indicated show the qualitative features.

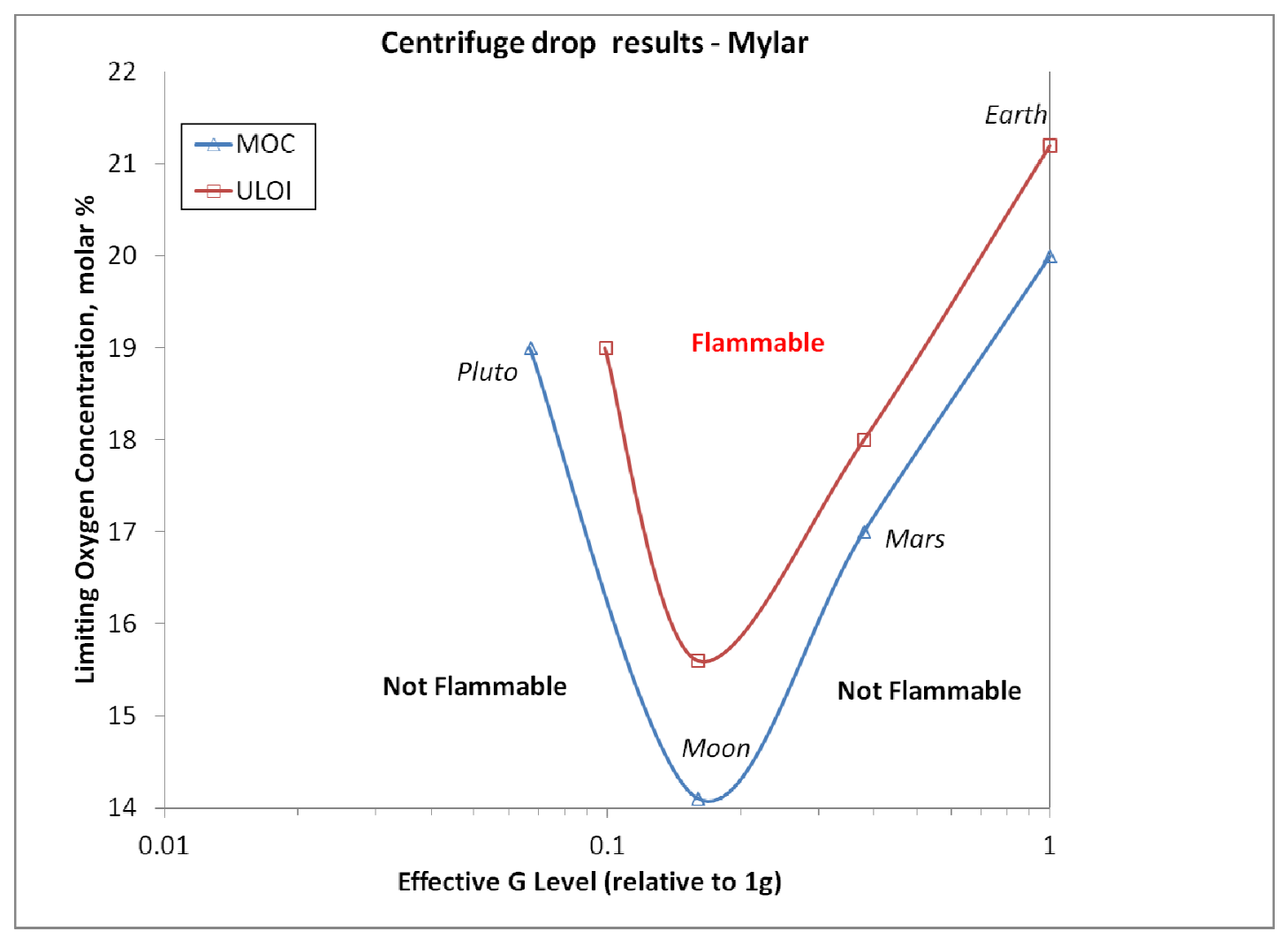

Figure 7. Limiting Oxygen Concentration as a function of g-level for Mylar. For a given oxygen concentration, there is range of g-levels which will permit the flame to be sustained.

\section{Conclusions}

A series of drop tower tests has been completed to determine the upward flame spread oxygen concentration extinction limits of three materials at Martian buoyant flow gravity levels for comparison with upward normal gravity limits, Lunar gravity, and at microgravity (with forced convection). The limiting oxygen levels at Martian gravity were significantly lower than normal gravity (up to $5.75 \% \mathrm{O}_{2}$ lower), and typically between the normal gravity and Lunar gravity values. However, it should be noted that the low-g extinction limit criteria are not the same as $1 \mathrm{~g}$ due to time constraints in drop testing. This consistent trend of negative margins of safety on normal gravity flammability screening tests indicates that normal gravity material flammability screening tests may not be conservative and some materials tested to be safe for use in space may actually be flammable. If proven for more materials, this may indicate the need to include a factor of safety on $1 \mathrm{~g}$ flammability limits.

The limits are defined with consideration of a modified NASA STD-6001 Test 1 protocol. $^{2}$ That modified protocol measures the actual upward flammability limit (akin to the Limiting Oxygen Index (LOI)) for the material so that a more accurate assessment of the margin of safety of the material in the real use space environment can be made rather than merely qualifying materials as pass/fail in the worst-expected environments.

The centrifuge apparatus is a useful tool to achieve gravitational acceleration levels in a range not easily attainable in simple drop tower or aircraft experiments. Additional research projects could make use of the chamber for their own specific objectives. 


\section{Acknowledgments}

We are grateful for the support of the FPDS (Fire Protection, Detection, and Suppression) program at NASA Glenn Research Center under the direction of Gary Ruff and JSC's Lunar Surface Systems project office. Dan Gotti of NCSER at NASA GRC was responsible for the mechanical design of the centrifuge chamber. Eric Neumann and his staff at the NASA GRC Zero-Gravity Facility were instrumental in the successful conduct of this experiment.

\section{References}

1،Flammability, Odor, Offgassing, and Compatibility Requirements and Test Procedures for Materials in Environments that Support Combustion, NASA STD 6001, Test 1, Upward Flame Propagation,” formerly NHB 8060.1C, 1998.

${ }^{2}$ Hirsch, D.B. and Beeson, H.D., "Improved Test Method to Determine Flammability of Aerospace Materials," Halon Options Technical Working Conference, 2001.

${ }^{3}$ Hirsch, D.B. and Beeson, H.D., "Test Method to Determine Flammability of Aerospace Materials," Journal of Testing and Evaluation Vol. 30, Issue 2, 2002.

${ }^{4}$ Hirsch, D.B., Williams, J.H., Harper, S.A., Beeson, H., and Pedley, M.D., "Oxygen Concentration Flammability Thresholds of Selected Aerospace Materials Considered for the Constellation Program," Second IAASS Conference: Space Safety in a Global World, Chicago, 2007.

${ }^{5}$ Campbell, P.D., "Recommendations for Exploration Spacecraft Internal Atmospheres: The Final Report of the NASA Exploration Atmospheres Working Group”, NASA JSC-63309, 2006.

${ }^{6}$ Lewis, J.F., Barido, R.A., and Tuan, G., "Crew Exploration Vehicle Environmental Control and Life Support Fire Protection Approach,” International Conference on Environmental Systems, SAE 2007-01-3255, 2007.

${ }^{7}$ Lekan, J., "Microgravity Research in NASA Ground-Based Facilities," NASA TM 101397, NASA LeRC, also AIAA-890236, 1989.

${ }^{8}$ Ferkul, P.V. and Olson, S.L., "Zero-Gravity Centrifuge Used for the Evaluation of Material Flammability in Lunar Gravity," Journal of Thermophysics and Heat Transfer, Vol. 25, No. 3 (2011).

${ }^{9}$ Sauers, D.G., "The Effects of Forced Air Flow and Oxygen Concentration on Flammability, Smoke Density, and Pyrolytic Toxicity," Journal of Fire and Flammability, Vol. 7, 1976, pp. 181-199.

${ }^{10}$ T'ien, J.S., "Diffusion Flame Extinction at Small Stretch Rates: the Mechanism of Radiative Loss," Combustion and Flame Vol. 65, No. 1, 1986, pp. 31-34.

${ }^{11}$ Steinberg, T.A., Wilson, D.B., and Benz, F.J., "Microgravity and Normal Gravity Combustion of Metals and Alloys in High Pressure Oxygen," Flammability and Sensitivity of Materials in Oxygen-Enriched Atmospheres, Vol. 6, ASTM STP 1197, edited by D.D. Janoff and J.M. Stoltzfus, American Society for Testing and Materials, Philadelphia, 1993. 